\title{
ERRATA
}

\section{Electrostatic Mechanism of Survival of Virulent Aeromonas salmonicida Strains in River Water

\author{
D. K. SAKAI
}

Hokkaido Fish Hatchery, Katakashiwagi 3-373, Eniwa, Hokkaido 061-14, Japan

Volume 51, no. 6, p. 1343, abstract, line 3: "virulent" should read "avirulent."

Page 1344, Table 1 , column 4 , lines 3 and 4 : " $<10^{8}$ ", should read " $>10^{8}$."

Page 1344, column 1, line 18: "10 min" should read "100 min."

Page 1344, column 2, Results, line 14: "3\% sodium chloride solution and within 7 days. . . ," should read " $3 \%$ sodium chloride solution. Total loss of viability occurred in 5 days in distilled water or $3 \%$ sodium chloride solution, or within 7 days. .."

\section{Inhibitor Studies of Dissimilative Fe(III) Reduction by Pseudomonas sp. Strain 200 ("Pseudomonas ferrireductans") \\ ROBERT G. ARNOLD, THOMAS J. DICHRISTINA, AND MICHAEL R. HOFFMANN \\ California Institute of Technology, W. M. Keck Laboratories, Pasadena, California 91125}

Volume 52, no. 2, p. 383: The correct version of Fig. 1 should appear as printed below.

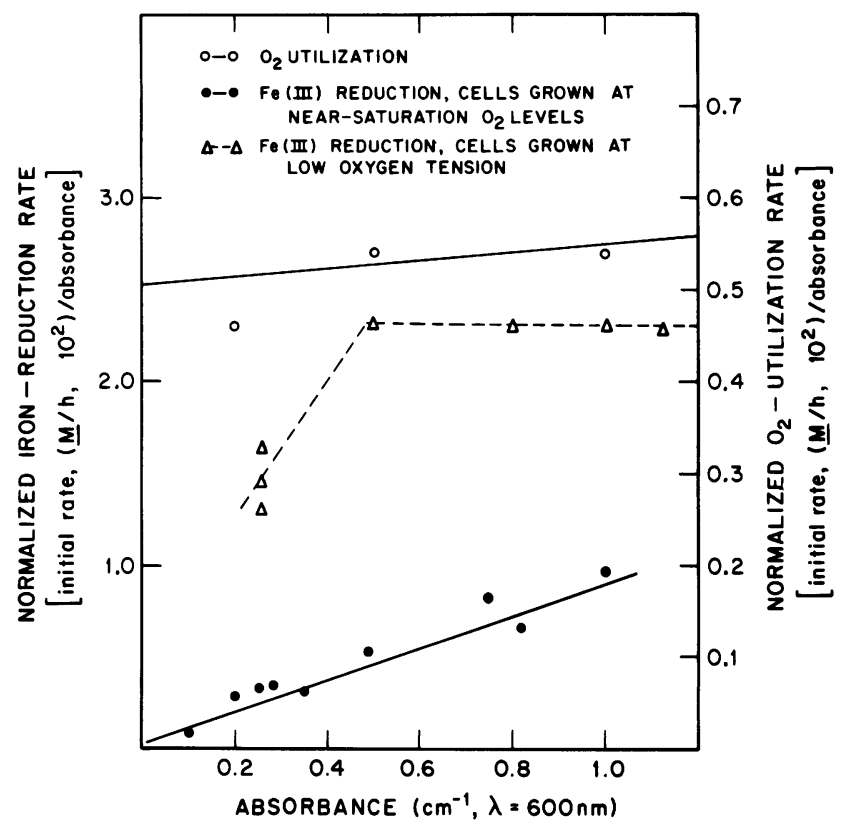

